\title{
Borboletas em lâmpadas: o coletivo escolar e a subjetivação dos educandos
}

\author{
Cláudia Aparecida dos Santos ${ }^{1}$ \\ Ireno Antônio Berticelli ${ }^{2}$
}

\begin{abstract}
Resumo
Este artigo visa problematizar os modos pelos quais as culturas contemporâneas vêm significando, por suas manifestações, a expressão da vida. Busca refletir sobre a sociedade e, por extensão, a escola e os modos de subjetivação em que se constituem os indivíduos/educandos, bem como identificar alguns dos fatores condicionantes que determinam a existência de modelos paradigmáticos dominantes em cada época. A análise transita por entre a tênue fissura que demarca a modernidade e a pós-modernidade. Assim, busca identificar seus possíveis fluxos e desdobramentos na sociedade líquida a que se reporta Bauman e a manifesta hegemonia do consumo anunciada na sociedade de consumo por Baudrillard.

Palavras-chave: Educação; Subjetividade; Subjetivação; Educação e Pós-modernidade.
\end{abstract}

Buterflies around lamps: the school colective and the subjectivation of the students

\section{Abstract}

This article aims to question the ways by which contemporary cultures are significating, by their manifestions, the expression of life. It seeks to reflect on society and, by extension, school and the ways of subjectivation whereby the individuals/students, just as well to identificate some conditioning factors determining the existence of dominating paradigmatic models in each period. The analisys passes through the tenuous fissure which delimits modernity and postmodernity. So, it aims to identify her possible flows and developments in liquid society reported by Bauman and the evident egemony of consumtion announced in consumer society by Baudrillard.

Keywords : Education; Subjectivity; Subjectivation; Education and Postmodernity.

\section{Introdução}

Borboletas em lâmpadas é uma metáfora que se aproxima muito da metáfora rizoma deleuze-guattariana (DELEUZE; GUATTARI, 1996), considerando que uma das características que determinam um rizoma é justamente um aglomerado com ausência de um ponto que designe seu começo ou o seu fim. Sendo assim, qualquer ponto de um rizoma pode ser ou estar conectado a qualquer outro ${ }^{3}$.

\footnotetext{
${ }^{1}$ Universidade Comunitária da Região de Chapecó (Unochapecó), Chapecó (SC); E-mail: claudiasartes@yahoo.com.br.

2 Universidade Comunitária da Região de Chapecó (Unochapecó), Chapecó (SC); e-mail: ibertice@unochapecó.edu.br.

${ }^{3}$ Outra aproximação desta metáfora pode ser feita com o enxame de abelhas descrito por Diderot em $O$ sonho de D'Alembert (1985, p.96-97) que, ao escapar da colmeia, pousa na ponta de um galho para formar uma infinidade de corpos individuais que formam um só corpo: o enxame. Diz: "Esse cacho é um ser, um indivíduo, um animal qualquer..." (p.97).
} 
Assim, a metáfora que propomos para interpretar a constituição do sujeito contemporâneo/pós-moderno/pós-estruturalista/hipermoderno, ou como melhor se deseja denominá-lo, é o aglomerado de borboletas noturnas que paira errante à luz de uma lâmpada, em noites escura e cálidas. Versa sobre o volume disforme, a massa contingente que se debate à procura da luz. Assim, na era dita pós-moderna, pós-estruturalista, na modernidade líquida ou hipermodernidade ou, o que se queira, caracteriza a cada dia mais a sociedade como um conglomerado de indivíduos, mas que forma corpo e não encontra o sentido da individualidade a não ser como parte desse todo social. Esta também é a forma pela qual os educandos - esses "chegantes" - constituem e destituem suas subjetividades, atraídos pelo lugar comum: a escola. Ou, então, capturados pela teia virtual, sob as condições que a microeletrônica propicia em que texto se liga a texto, que se liga a texto: o hipertexto, numa hiperteia, em que "borboleta" se junta a "borboleta", que se junta a "borboleta", atraídas por uma gigantesca luz: a world wide web, através do computador, pelo notebook, pelo celular, pelo iPad que outros chamam de tablet... Enfim, é no enxame global ou a colmeia global, digo, a "aldeia global" de Herbert Marshall McLuhan que as identidades emergem. É ainda possível um ato que institui um eu autônomo por força de um verbo conjugado na primeira pessoa do singular: cogito, (penso, em latim), para concluir para um ergo sum (portanto, existo), assim, na solidão de um solipsismo autoexplicado? Impensável, hoje. Notáveis pensadores-educadores já se encarregaram, de há muito, para reivindicar, através de consistente argumentação, que nossa identidade é resultado de uma infinidade de interações. Somos um eu caleidoscópico que replica o todo e em que o todo replica as partes, cometendo, mesmo assim, a metafísica da presença em seu transbordamento (DERRIDA, 2008) que não permite que cada um se perca no todo.

A reflexão aqui pretendida visa problematizar os modos pelos quais nossas culturas e, sobretudo, os sujeitos estabelecem sua atuação e expressão cultural e subjetiva. As borboletas, simbolicamente, tentam expressar o emaranhado contingente em que se estrutura a vida humana, em intenso e complexo fluxo, sobretudo no mundo contemporâneo, marcado por importantes mudanças de paradigmas que, por sua vez, desencadeiam outras mudanças sociais, culturais, tecnológicas etc.

Esta análise se propõe entender as composições culturais e sociais pelas quais se constituem/destituem os sujeitos: se constituem e se destituem, tal como o enxame das borboletas 
noturnas que formam corpo atraídas pela luz da lâmpada, em movimento constante e rizomático.

Partimos da percepção que após a fragilização da máxima de Galileu de que a natureza poderia ser traduzida em linguagem matemática, os paradigmas da complexidade, da autoorganização, da incerteza e do caos abrem caminho para outros determinantes para os novos modos de vida e de subjetivação. Neste sentido, o papel da educação também acompanha os fenômenos de mudanças profundas. Já não pode mais ater-se a uma formação apenas intelectualista, racionalista, "científica", em sentido estritamente moderno. Ali também os afectos precisam ser notados, precisam ser cultivados.

Consideramos, portanto, nesta discussão, que do abandono dos axiomas nos quais se pautava a vida moderna, à assunção de outros paradigmas que agora escrevem a pósmodernidade, talvez a questão ainda se preste a perguntar sobre nós mesmos, sobre o que sabemos. Para Lyotard, “[...] o saber pós-moderno não é somente o instrumento dos poderes. Ele aguça nossa sensibilidade para as diferenças e reforça nossa capacidade de suportar o incomensurável" (1988, p.17).

As narrativas que versam sobre o cotidiano, sobre os modos de subjetivação e a individualidade humana requerem que nos aproximemos dos meandros em que se estruturam e se formam os sujeitos. Elegemos, como recurso para tal feito, realizar um recorte deste itinerário. Fazemos isto ao reconhecermos a fenda que se abre, nas últimas décadas da nossa história. Tomamos a liberdade, em nossa busca, mesmo tendo a clareza de que as hipóteses com as quais vamos operar não são da ordem da sucessão progressiva e linear, de articular as ações de poder como formas de subjetivação firmadas em conceitos como os de poder + saber, aprendidos em Foucault (1979), bem como em suas possíveis manifestações nas formas líquidas propostas por Bauman (2001) e na manifesta hegemonia do consumo, no seio da sociedade de consumo caracterizada por Baudrillard (2005).

\section{O lugar do eu em Foucault}

O empreendimento de saber pelas quais se situa exatamente o pensamento de Foucault parece uma tarefa árdua, quando não sem sentido, por tratar-se de um autor que não permite ser enquadrado em uma única linha/escola ou corrente de pensamento. Também não se 
encontra nisto nosso intento. Objetivamos, sim, percorrer algumas das veredas na companhia do autor, na intenção de compreender os possíveis processos que formam o sujeito e armam, na contingência da vida, formas de existir. Fazemos à luz fugidia dos fogos da pirotécnica foucaultiana. Nada de muito duradouro e definitivo.

Partimos, em nossa investigação, inicialmente, no intento de trazer à luz perspectivas epistemológicas capazes de desnudar os processos constituintes da sociedade e do sujeito. Somos motivados pela percepção que Foucault, mesmo que de maneira assistemática, apresenta uma chave de como os saberes integrados a ações, "surfando" a linguagem, fazem o percurso em que se alargam da dimensão discursiva aos efeitos de verdade e regem as esferas sociais.

Perguntamo-nos, neste momento, como abeirar-nos das inquietantes e descontínuas andanças de Michel Foucault. Grande parte dos especialistas e estudiosos da obra do francês costumam postular três etapas do pensamento do autor, denominadas: arqueologia: que tem por pressupostos a constituição histórica de certos saberes, na busca de perceber quais são as condições, as possibilidades ou os elementos de poder nas quais os discursos se firmam. $O$ estudo é muito relevante até a década de 70 , quando da guinada do pensamento foucaultiano para a entrada da segunda etapa: genealógica, que trabalha em oposição à unicidade das narrações históricas e a terceira fase, a ética, que seria com o devido cuidado de não baratear seu intento, a união dos métodos anteriores, voltados ao sujeito arqueogenealógico (DAVIDSON, 1992 apud VEIGA-NETO, 2003, p.43).

Logo, o discurso, o poder e a subjetivação apresentados por Foucault fundem-se num vigoroso encaixe. Trata-se da possibilidade argumentativa das problematizações por ele levantadas, não podendo, deste modo, simplesmente, considerar a condição de superação de uma fase pela anterior, pois estas "[...] englobam-se em círculos cada vez mais amplos, mas não se substituem, absolutamente" (MOREY, 1991, p.16).

Primeiramente, cabe o entendimento de que não podemos pensar sob a ótica de Foucault sem aproximarmo-nos da história. O autor, em sua vereda filosófica, embarca a existência e a atuação humana na balsa contingente e oscilante da história. Na visão de Foucault, cada época estabelece seus próprios artefatos para significar o que pensa, condicionada absolutamente pelos saberes nos quais se encontram enraizadas sua condição histórica e suas possibilidades de existir. 
Dito de outro modo, para Foucault (2009), cada época tem uma regra, uma epistéme, responsável pela formação de seus próprios objetos, sujeitos, conceitos, culturas etc. E a história se escreve na fluidez ilimitada dos acontecimentos. Entretanto, a crítica desenvolvida por Foucault vincula-se invariavelmente à história. Tal abordagem abre precedente e oferece elementos para pensar o passado ou presente como sendo um emaranhado de acontecimentos jogados sobre uma grande teia, cuja compreensão ou, a percepção (destes acontecimentos) está invariavelmente comprometida com os poderes e os saberes que os integram.

Podemos dizer, assim, que a história se escreve por sobreposição, num compósito: a partir de composições de saberes sobre saberes, poderes sobre poderes, lugar onde todos são agentes ativos. E a verdade ou seus efeitos nada mais é/são que um consenso. Aliás, o deslocamento operado pelo autor passa fundamentalmente por uma problematização das categorias, a partir das quais, com o entrelaçamento das relações de poder e saber, vê-se cristalizar, ou solidificar, segundo Bauman (2001), a força da ação sobre as ações, definindo estados de dominação e controle.

A afirmativa segundo a qual a problemática da constituição do sujeito encontra-se no cerne de todo o trabalho de Foucault, por vezes explicitada nas práticas do saber, ora configurado nas relações de poder e, mais para o final de sua vida, expressada nas técnicas de cuidado de si, parece pertinente. É o sujeito, analisado em sua constituição histórica, um dos, senão, o principal alvo das análises do autor que em uma de suas entrevistas (FOUCAULT, 1995) reconhece a centralidade do sujeito em suas pesquisas. A subjetividade concebida por Michel Foucault não surge como um axioma natural, imposto ao homem como efeito de sua condição simplesmente de ser. Todos os saberes humanos, os valores e a própria identidade são auferidos como contingências históricas.

Trazendo a discussão para o campo educacional pela perspectiva da pesquisa sobre o tema currículo, que no declínio da década de 1980 para a década de 1990 se tornou importante eixo de tematizações educacionais, constatamos, a cada leitura, que o currículo se constitui campo de produção identitária, ressalvados bem poucos casos. É notável, neste campo do saber, a obra de Marlucy Alves Paraíso, intitulada Currículo e mídia educativa brasileira: poder, saber e subjetivação (2007) que originariamente foi sua tese de doutoramento, orientada pelo importante curriculista Antônio Flávio Moreira. A base teórica, de vertente foucaultiana, deu 
sustentação a vasta e sólida argumentação em favor da produção das subjetividades, através das diferentes mídias. Não é ocioso lembrar o quanto do tempo da infância, da adolescência e mesmo da vida adulta é passada, hoje, em intensa interação midiática que, sem dúvida, se constitui em um conjunto poderoso de artefatos que compõem o cenário mais amplo da produção das identidades. Trata-se da "escola heterotópica" que caracteriza e direciona a educação na pós-modernidade.

Foucault mostra como, ao longo dos tempos, em diferentes épocas, surgiram condições específicas de formações discursivas ou jogos de poder que legitimaram os meios pelos quais dimana o curso da vida.

E este ponto é bastante delicado, pois pode levar a entender o sujeito como um ser assujeitado, passivo, produto de uma época, de um tempo ou, então, de uma máquina, de um artefato, como o currículo escolar. O fato da subjetividade estar imbricada em condicionantes históricos anularia a ideia de um indivíduo consciente e completamente livre em suas escolhas e ações: o sujeito kantiano autônomo, de maioridade. O educando seria, neste caso, uma vítima do sistema escolar/da mídia, absorvido pelo "grupelho"4. Por outro, reconhece que os princípios que norteiam as ações humanas não são perenes, não habitam ares de transcendência. Eles apenas acontecem. Para Foucault (1979) a casualidade também constitui uma categoria na produção dos conhecimentos.

A problemática que movimenta as análises de Foucault (1979) precisa ser entendida num contexto complexo. Por vezes, afirma que os nossos sistemas de agir e pensar são sedimentados por fatores históricos, pelo poder disciplinador e normalizador, e são configurados sob uma espécie apurada de formação moral e ética, capaz de reprimir as experiências pessoais, colocando-as sob vigilância. Enumerar e classificar os indivíduos, conduzir seus passos, suas ações e determinar os lugares de cada sujeito na esfera social, com base em itinerários preexistentes, eis a compreensão foucaultiana da subjetivação. Ainda assim, reconhece a possibilidade de um sujeito liberado do jugo do saber moderno, dos arquétipos que lhe foram conferidos, tendo como única saída o entendimento de como estes mecanismos se criaram. Nesta empreitada, a escola, o quartel, o hospital, a prisão ... se caracterizam por atividades de

\footnotetext{
${ }^{4}$ No original francês "groupuscules" a que se refere Félix Guattari na obra Revolução molecular: pulsações políticas do desejo (1987).
} 
enumeração, classificação, de divisão, de separação que marcam a modernidade. “Meu papel [...] é o de demonstrar às pessoas que elas são muito mais livres do que pensam ser; que elas têm por verdadeiros, por evidentes alguns temas que foram fabricados num momento particular da história, e que essa suposta evidência pode ser criticada e destruída" (FOUCAULT, 2004, p.295).

Foucault aguça seu olhar para a contemporaneidade e preconiza, em seus últimos textos, a ideia de uma possível reconstrução da moral greco-romana. Traz à tona a experiência arraigada ao cuidado de si, atribuindo-Ihe papel crucial, cuja função seria questionar as identidades préfabricadas e a hegemonia dos códigos morais estatuídos como máximas. Coloca o sujeito, então, no centro da reflexão.

A ética de Foucault exposta em seus últimos trabalhos ajuíza sobre o que impregna uma relação de poder. Sua tarefa soa urgente em propor ao indivíduo a recusa da universalidade. Explica que a tentativa da construção de uma moral comum, normativa e totalitária está associada intimamente à solidificação do poder e assegura que a aceitação de arquétipos de vida pré-determinados, sob os quais todos devam submeter-se, "parece catastrófica". Entenda-se, aqui, também o imperativo categórico kantiano.

Diante do exposto, evidencia-se que as relações de poder e os modelos nos quais a vida se processa caminham lado a lado. A necessidade da construção do saber, o seu acúmulo e a imperativa disseminação deste saber produzem as feições que tomam os indivíduos. E suscitam os diálogos que a sociedade aceita sem suspeitar de seus intentos. Estes saberes, então, passam a operar, por sua vez, como paradigmas assumidos como verdades absolutas. Os currículos escolares assumem com intensidade esta função. A obra de Foucault, ao desnudar a conexão entre "efeitos de verdade" e os regimes de poder, ajuda a pensar que os modos de vida não preexistem a eles mesmos, e que as subjetividades são frutos dos percursos e percalços destes mesmos modos de vida, em contínuo movimento.

Deleuze e Guattari esclarecem:

Cada centro de poder é igualmente molecular, exercendo-se sobre um tecido micrológico onde ele só existe enquanto difuso, disperso, desacelerado, miniaturizado, incessantemente deslocado, agindo por segmentações finas, operando no detalhe e no detalhe do detalhe. (1996, p.97). 
Em consonância com os autores, podemos dizer que as subjetividades são forjadas a partir dos ditames do poder/saber, pelo qual os sujeitos agem, reagem e interagem, seja por conformidade ou por oposição às regras estabelecidas. Desde a mais tenra idade, os humanos encontram-se envolvidos por complexos sistemas de subjetivação. E a escola não deixa de ser uma verdadeira epígrafe na escritura da historicidade de cada ser humano, entenda-se por "escola" as mais diversas formas e níveis de sistematização do ensino dito formal ou informal, pois é aí que se engendram e classificam as mais sofisticadas e "racionais" máquinas de subjetivação e de produção de regimes de verdade, ao par de outras tantas instituições.

A partir desta visada, nota-se que as regras elaboradas para fundamentar cada regime de poder, bem como firmar para cada época uma epistéme não se dá de modo linear, sem rusgas ou ruídos. Neste sentido, é importante sublinhar que não assumimos a condição de sermos o que somos, moldados passivamente, por formas de poder unicamente externas. Entendemos, sim, que as relações de poder são constituídas por tensões, nas quais uns procuram sobrepor-se a outros, alcançando êxito na medida em que se evanesce a resistência e os indivíduos e as ações tornam-se previsíveis.

Para Foucault (1979, p.29-30): “[...] não há constituição de poder sem constituição correlata de um campo de saber, nem saber que não suponha e não constitua, ao mesmo tempo, relações de poder". A compreensão dos processos nos quais se constitui a subjetivação na relação dos sujeitos consigo e com os outros, frente às forças que movimentam ininterruptamente processo de sobreposições e fragmentações de si e da própria cultura deixa claro que quando há mudanças nas relações de poder-saber, como consequência, ocorrerá mudanças nas formas de subjetivação, como marca da condição contingente da vida humana.

Mas, retomando nossa metáfora, que também intitula este texto, "Borboletas em lâmpadas", ela nos coloca perante essa massa disforme e contingente que se movimenta de modo desenfreado, não em linha reta, não de modo absolutamente previsível, mas na confluência de um eixo central. As borboletas de que falamos movem-se orientadas pela luz. Mas apenas olhando bem de perto, no "detalhe do detalhe" é que poderíamos compreender seu bater de asas. E quem de nós, por uma razão ou por outra não se deparou com um "bando" de crianças, num pátio de escola, num movimento muito similar ao das borboletas em causa, obedecendo a uma lógica interna das brincadeiras, lógica indecifrável, ao menos, num primeiro 
momento. Que lógica será essa que mantém o grupo de crianças coeso? Que complexa teia é uma turma de crianças em intensa interação? Com certeza, encontramos, aí, a lógica dos jogos de linguagem a que se referem Wittgenstein e, depois deles, tantos e bons pensadores como Habermas, Hans-Georg Gadamer, só para citar alguns. Talvez seja essa lógica difusa que deixou um personagem de Kafka [19...?], em O processo, em situação embaraçosa, ao querer passar pelo meio de um grupo de crianças que se interpunha a seu caminho. E, no embaraço, pensou consigo mesmo se Ihes daria doces ou se Ihes daria uma varada. O personagem se viu, certamente, ante o desafio de decifrar a lógica constitutiva do grupo de crianças, no meio do qual teve, sem dúvida, dificuldade de se mover. A linha reta da travessia pelo meio do "bando" pareceu-Ihe, certamente, a mais inadequada ante um grupo humano orientado por uma lógica difusa: tão difusa como a das borboletas em torno de lâmpadas. Isto tudo nos leva a meditar sobre a profissão docente de todos os níveis. Com certeza, não funciona sempre, nesta profissão, a lógica linear. Pois não é linear o intenso pulsar do mundo da vida que constitui o cenário do cotidiano deste profissional, o professor.

\section{O abreviamento do vazio: Zigmunt Bauman}

A racionalidade moderna, marcada pela procura de certezas científicas e pela definição de modelos ideais, caracteriza a centralidade de um período no qual se confiou na elevação de uma verdade totalizante, capaz de reduzir as diferenças presentes nos indivíduos e nas sociedades. Até a emergência da modernidade, acreditava-se na homogeneidade do mundo, sob modelos legítimos. Mas, na busca pelo único, deu-se o encontro com o múltiplo, com a ambivalência, com a complexidade. E, na quebra deste desígnio universalista, viu-se a diluição do modelo uno de sociedade para, em consequência, nos darmos conta de uma enorme massa de individualidades.

A tentativa de situar algumas das especificidades que deram rosto à sociedade moderna permite também identificar os sintomas que vazam pela cultura como possíveis significadores da sociedade contemporânea. O fato é que a complexidade da experiência humana, que o poder gestor da ordem, na modernidade, almejou abolir, escorreu por entre os dedos. A sociedade pós- 
moderna, então, surge caracterizada por este contexto ${ }^{5}$. O cenário é de transitoriedade, os princípios que antes regiam a vida cotidiana do indivíduo e da sociedade vão sendo gradativamente desconstruídos.

Frente a este quadro, pensar as questões que inscrevem a contemporaneidade não é percorrer um caminho fácil, pois não se trata de um percurso já consolidado. Seus temas e questões não têm um corpo teórico definitivo. Todavia, se é possível pensar um único ponto comum capaz de sustentar as distintas reflexões que dizem respeito ao que chamaremos de pósmodernidade ${ }^{6}$, considerando que o termo "pós" refere-se à sua temporalidade, ou seja, se é possível pensar o que configura como o eixo principal no mundo pós-guerra, pós-industrial, pósrevoluções tecnológicas e midiáticas como marca do nosso tempo, resta como resposta o "caráter de mudança" (LYON, 1998).

Sendo assim, ao aproximarmo-nos da pós-modernidade ou modernidade líquida, segundo Bauman (2001), temos como intuito significar este momento de mudança. Buscamos, inicialmente, entender a fase que sobreveio à condição moderna da existência humana. Nosso intento não está em buscar uma linearidade progressiva, ou qualquer coisa que rigidamente descreva ou represente a "superação" da modernidade, mas algo que potencialize ou permita de algum modo significar nosso tempo.

Sabemos que responder às idiossincrasias da nossa época é realmente percorrer um terreno instável. Mas iniciamos por uma colocação de Lyotard, quando disse, certa vez, considerar a pós-modernidade talvez se trate da busca por outras respostas $(1988$, p.17). E buscar outras respostas exige também questionar sobre o saber, sobre o que sabemos realmente.

Berticelli (2006, p.143) vai além: faz pensar que talvez se trate de questionar sobre os saberes, assim, no plural. O professor Berticelli permite considerar a cultura, o sujeito e o saber

\footnotetext{
5 “O neologismo pós-moderno tinha um mérito: salientar uma mudança de direção, uma reorganização em profundidade do modo de funcionamento social e cultural das sociedades democráticas avançadas. Rápida expansão do consumo e da comunicação de massa; enfraquecimento das normas autoritárias e disciplinares; surto de individualização; consagração do hedonismo e do psicologismo; perda da fé no futuro revolucionário; descontentamento com as paixões políticas e as militâncias - era mesmo preciso dar um nome à enorme transformação que se desenrolava no palco das sociedades abastadas, livres do peso das grandes utopias futuristas da primeira modernidade" (LIPOVETSKY, 2004, p.52)

${ }^{6}$ O filósofo Jean François Lyotard, em A condição pós-moderna (1979), foi quem divulgou mais amplamente o conceito de pós-modernidade, mesmo não sendo seu criador, utilizou o termo para se referir o abandono das grandes narrativas, uma vez que não há, segundo afirma, uma metanarrativa capaz de tornar um discurso aceito por todas as culturas.
} 
agora ditos no plural. Para o autor, que lê o mundo "Sob a ótica da complexidade [...]", os saberes encontram, com a pós-modernidade, lugar para regressar, pois "[...] o mundo está liberto das amarras matemáticas". E, na sequência, interpretando Prigogine e Stengers $(1984)^{7}$, Berticelli (2006, p.259) diz:

A nova aliança tem por característica principal unir o que o homem moderno separou: o mundo do homem/da mulher. Os saberes retomam seu lugar. A exclusividade do saber more geometrico, more mathematico perde sua hegemonia mantida por séculos. Fica claro que os saberes nunca deixaram de existir de modo plural, [...].

Esta assertiva permite concluir que a pós-modernidade instaura-se como território fértil e complexo. Abre espaço para os que a modernidade outrora excluiu, deixa entrar os que estavam de fora. Para o sociólogo contemporâneo Bauman (2001) tais mudanças também são evidentes, contudo, prefere o termo modernidade líquida, e o utiliza como metáfora para significar tais transformações. A propósito, abalizados autores, por vezes, negam pura e simplesmente que haja de qualquer maneira, uma "pós-modernidade". Porém, por se tratar de pessoas muito bem informadas dificilmente não ressalvam algo assim como: "Mas que há, sim, algumas questões importantes postas pelo que se denomina 'pós-modernidade', sem dúvida há". Pois bem. Podemos encurtar muito os caminhos, ao invés de entrar em polêmica com tão ilustradas figuras, reconhecendo que, de fato, os que estamos preocupados com o que se denomina "pós-modernidade", "modernidade líquida", "hipermodernidade" e, por aí a fora, é justamente com essas "questões importantes". Nada além disto.

Bauman (2010) elaborou argumentos que em determinados momentos seguem uma linha próxima ao pensamento já exposto por Michel Foucault. Vê a modernidade sob a égide do poder disciplinador, cuja analogia do saber-poder se configura na fórmula particularmente moderna de controle social que orienta a construção de um pretenso mundo ordeiro e idealizado. Também para Bauman (2010), a estrutura e a ordem são contingentes, nada mais que produções humanas criadas com a finalidade de garantir a previsibilidade e suprimir o caos. A mente moderna nasce alimentada pela ideia de que o mundo poderia ser preenchido a

\footnotetext{
7 PRIGOGINE, I.; STENGERS, I. A nova aliança: metamorfose da ciência. Trad. Miguel Faria e Maria Joaquina M. Trincheira. Brasília: Ed. da UNB, 1984.
}

Periódico Horizontes - USF - Itatiba, SP - Brasil - e020071 
partir de um único molde e repetido inúmeras vezes, tendo por aliado um rigoroso trabalho de separação e aniquilamento dos "refugos" (BAUMAN, 1999). Assim, o seu pensamento aproximase de Foucault (1979) quando sinaliza que os detentores do poder orientam racionalmente os rumos da sociedade. Para o sociólogo, o sonho moderno trouxe em seu bojo seu antagonista, o seu contrário, a desordem, o caos, a ambivalência, a complexidade e o vazio. Para Bauman (2001), na modernidade, a responsabilidade individual era praticamente inexistente, devido à falta de autonomia. Na modernidade líquida, embora esta ofereça a aparente possibilidade da constituição de um sujeito particular, também esboça, na falta de referência, o desafio do convívio coletivo e mesmo particular. Desde Nietzsche, não temos mais um arquétipo seguro e tranquilizador de como se deve viver: “[...] os mal-estares, aflições e ansiedades típicos do mundo pós-moderno - resulta do gênero de sociedade que oferece cada vez mais liberdade individual ao preço de cada vez menos segurança. Os mal-estares pós-modernos nascem da liberdade, em vez da opressão" (BAUMAN, 1998, p.156).

Se a modernidade exigia a assimilação e adaptação a um padrão universal, a era pósmoderna, ao afirmar a diferença, recusa a semelhança e a convivência justificadas pela rejeição de imposições autoritárias, acentuadas pela competição.

A metáfora da liquidez desenvolvida pelo polonês reflete as maneiras que a humanidade desempenha a sua compreensão da realidade e interage, movendo-se em plenas forças para permanecer no mesmo lugar (BAUMAN, 2009). O sociólogo apresenta, por meio de metáfora, características importantes para se pensar a sociedade e os sujeitos. Para a sociedade moderna, a forma sólida, para a outra modernidade a forma líquida. Para a primeira, a ordem, a rigidez. Para a segunda, a ambivalência e a fugacidade que levam ao descarte quase que imediato de um bem material ou imaterial, deflagrando no individuo o medo de também ser jogado no lixo. Constata-se, também, que o modelo político-econômico migrou da produção para o consumo. Vive-se a terceira globalização cujo mercado subsume o poder. O avanço tecnológico e midiático, a expansão da economia capitalista, os neoliberalismos, por sua vez, ditam o ritmo da vida e amoldam os sujeitos líquido-modernos. Surge, gradualmente, um volumoso número de rejeitados. Migra-se fervorosamente da "[...] exploração para a exclusão" (BAUMAN, 2005, p.47); ou "A vida na sociedade líquido-moderna é uma versão perniciosa da dança das cadeiras, jogada para valer. O verdadeiro prêmio nessa competição é a garantia (temporária) de ser excluído das 
fileiras dos destruídos e evitar ser jogado no lixo" (BAUMAN, 2009, p.10).

De acordo com essa visão, pode-se dizer que o consumo impera como a nova "ordem". E dela resulta potente mecanismo de autoconstrução identitária. Neste sentido, as ações individuais, sob o signo de uma suposta liberdade na pós-modernidade, ou modernidade líquida, como prefere Bauman (2001), incluem como característica fundante, na vida particular e coletiva, a efemeridade e urgência das ações e das coisas. Ser livre confunde-se com a ter a liberdade (ou o poder) de consumir o que se deseja. Há, mercê da força econômica globalizada, um enfraquecimento facilmente perceptível até mesmo dos poderes políticos e muito mais ainda, um enfraquecimento do/da poder/autoridade da escola, da educação, dos educadores em geral.

$\mathrm{Na}$ era líquida, como na moderna, os apêndices do poder se alastram e se instalam com vigor na formatação das subjetividades. Zygmunt Bauman, em seu livro Vida líquida, atenta para o papel de destaque do consumo como definidor da identidade do indivíduo, na sociedade contemporânea:

A resposta à questão relativa à sua identidade não é mais um "engenheiro da Fiat (ou da Pirelli)", ou um "servidor público", ou um "mineiro" ou um "gerente de loja da Benetton", mas, como num recente comercial descrevendo uma pessoa que usaria o prestigioso logotipo nele anunciado, alguém que "adora filmes de terror, bebe tequila, usa saiote escocês, é fã do Dundee United F.C., da música dos anos 1980, da decoração dos anos 1970, viciado nos Simpsons, cria girassóis, a cor favorita é o cinza-escuro, fala com as plantas". No número seguinte da revista, aparece outra pessoa (...) Os dois "atestados de identidade" levam à mesma conclusão: "tudo está no detalhe". Desnecessário dizer que todos os detalhes mencionados e qualquer outra coisa mencionável estão disponíveis nas lojas (BAUMAN, 2009, p.114-115).

À metáfora arquitetada por Bauman (2001) cabe a incumbência de problematizar os processos que identificam e produzem os eixos constituintes das culturas em seus formatos sólido e líquido. Neste contexto, podemos dizer que contemporaneidade está embebecida na fluidez dos acontecimentos. Que somos severamente escravizados por nossa própria história. Atualmente, a liberdade e os desejos individuais, reprimidos outrora, tomaram para si a governabilidade e são os atuais balizadores das sociedades. Tal acepção permite que nos voltemos de outra possível luz que se acende e sob a qual se aglomeram as borboletas de agora. 


\section{O que já não somos: em Baudrillard}

A concretização do mundo globalizado se dá cada vez mais centralizada nos desejos. $\mathrm{Na}$ terceira globalização, o poder de mercado assume lugar central e aponta para novas maneiras do capitalismo subsistir. Na ditadura das possibilidades infinitas, apoiamo-nos no pensamento fundante de Baudrillard (2004), que diz que todo objeto tem um valor, além do valor de uso e do valor de troca, mas acima destes, um valor simbólico. A posição defendida por Baudrillard (2005) foi sendo construída no chão que levava a sociedade metalúrgica (do trabalho) para a sociedade semiúrgica (dos símbolos). Neste sentido, o autor apresenta um importante estudo relativo à acepção de compreender a atualidade. Entende, assim, que uma lógica que valoriza o relativismo e a indiferença tende para a codificação da vida. Concebe sua crítica a partir não mais da produtividade, que era a questão central da modernidade, mas, sim, da "consumidade", o imperioso desejo de consumir. Quando situamos o surgimento da pós-modernidade, vemos que esta determina e encontra suporte no desenvolvimento tecnológico, midiático e na urgência dos saberes, das trocas simbólicas. O indivíduo, a sociedade de modo geral não mais se movimentam regidos pela força de trabalho ordeiro, mas pela força de consumo desenfreado. Para o autor, as identidades e as experiências deixaram de ser aquelas do trabalho e passaram a ser as do consumo. Para Baudrillard (2005, p.11), na pós-modernidade, “[...] o consumo surge como modo ativo de relação, como modo de atividade sistemática e de resposta global, que serve de base a todo o nosso sistema cultural". Para Baudrillard (2005, p.17), "transformou-se a relação do consumidor ao objeto: já não se refere a tal objeto na sua utilidade específica, mas ao conjunto de objetos na sua significação total". E educação acaba profundamente afetada por este mesmo cenário: a mercantilização da educação é um fato. O grande mercado, tão logo se apercebeu disto, viu na educação um vasto território de investimento. E sabemos que, hoje, o ensino de todos os níveis se subordina, em boa parte, a gigantescos conglomerados empresariais de abrangência internacional, o que acaba também produzindo características mercantis no próprio perfil da escola de todos os níveis e este perfil também se reduplica nos "operadores" da educação, seus empresários, bem como se exige um perfil compatível com esse mercado dos próprios professores e professoras.

Essa intima relação entre a posse do objeto consumido, e a "montagem" da própria 
identidade, indica que na sociedade de consumo qualquer pessoa pode ser classificada e medida a partir dos objetos que possui: "[...] a qualidade específica do objeto, seu valor de troca, depende do domínio cultural e social. Sua singularidade absoluta ao contrário lhe vem do fato de ser possuído por mim - o que me permite reconhecer-me como ser absolutamente singular" (BAUDRILLARD, 2004, p.98).

Na sociedade dos símbolos, estranhamente, o foco de interesse se centra não no objeto a ser consumido, pois este perdeu seu valor (de uso e de troca). O interesse está no código de signos que o ajuíza, e seu valor está associado ao sentido que este empresta à experiência, seja individual ou coletivamente, na interminável busca de achar, em meio a objetos, o que já não se é mais.

Quando, a propósito de Foucault (1979), reportamos as manifestações de poder às formas de subjetivação, tínhamos, nas forças de ação sobre ação, a principal forma atuante e unificadora de identidades. Atentamos, agora, para o consumo como peça de autoconstrução identitária e subjetiva, confrontando os sujeitos, oferecendo-Ihes múltiplas identidades possíveis, com as quais podem se identificar, ainda que provisoriamente.

Na sociedade de consumo, a ilusão de liberdade e originalidade alimenta a máquina invisível de uma potente forma de poder. A promessa de atender a todos os desejos humanos de maneira plena e jamais pensada por qualquer outra sociedade do passado ocupa lugar de destaque. De fato, o que não pode passar despercebido é que a não possibilidade de realização destes desejos é o agente principal desta história e sua obsolescência. E a superação constante dos produtos consumidos é a premissa, no propósito de manter viva a vontade infinita de consumir, animando, assim, a "corrida dos ratos".

Denota-se que o sujeito pós-moderno de Baudrillard (1997), assim como o sujeito de Foucault (1995), não tem identidade fixa, pré-existente. Nos tornamos artefatos culturais globalmente constituídos. O que chama a atenção é que a base da vida social, mais uma vez, não está arraigada nas necessidades básicas para a sobrevivência, ou presa às necessidades puramente econômicas, mas também se mesclam a valorações pessoais, desejos e estilos de vida.

A existência humana, mais do que em qualquer outra época, arrebentou as rédeas que a prendiam e perdeu-se em simulações complexas que, conscientemente ou não, estão implicadas na manutenção de uma nova forma de controle. Temos, aí, a presença íntima da analogia entre 
formas de poder e a constituição do sujeito doutrinado para ser "livre", com toda a sinonímia que a palavra liberdade ganha na pós-modernidade, incorrendo seu fracasso na pena da repressão ou da exclusão social. Neste sentido: “[...] a oferta de satisfação só permanecerá sedutora enquanto o desejo continuar irrealizado" (BAUMAN, 2009, p.106).

Se considerarmos as questões circundantes que animam a sociedade do consumo, acharemos como resposta uma roda de camundongos em contínuo e imperioso giro, movendose na tentativa inútil de suprir necessidades que são psicológicas ou culturais. A partir de Baudrillard (2005), podemos pensar que as relações de consumo transformam o homem, interferindo em sua identidade e em suas relações. Se, na modernidade, a perspicácia do poder estava vinculada ao trabalho ordeiro, na pós-modernidade, sob a ótica do autor, apresenta-se sob inúmeras vestes do consumo desenfreado.

Baudrillard (1991) nos apresenta a cultura do simulacro, em que o real é perdido, os significados são abolidos pela impregnação dos signos. Perdeu-se a essência do ser. Afastado da natureza, atrelado indissociavelmente ao sistema, o homem contemporâneo tem por seu reflexo excessos deformados de pretensa realidade.

\section{Considerações finais}

Estas são garatujas traçadas na descontinuidade da história, em meio à crise dos valores éticos, das mudanças nos sistemas de trabalho acentuadas pela intensificação da globalização. Em contrapartida, o individualismo, o universal, em confronto com o singular e o volume desorientado de informações identifica o cenário da contemporaneidade e alimenta a pósmodernidade. São os traços inseguros destes tempos conturbados que educadores estão tateando, à busca de um caminho educativo, sabendo que tal caminho é "Caminho de bosque" , ou seja, caminho que leva a todos os lugares e a lugar nenhum definitivo e final. E este singular saber de mover-se num meio rizomático se põe como uma demanda que, em outros tempos, sequer poderia ter sido sonhada. Nossa própria identidade se faz, se refaz e se desfaz para refazer-se, mais adiante, pelos caminhos que caracterizamos com o título da obra de Heidegger

\footnotetext{
${ }^{8}$ Referência à obra de Martin Heidegger (1995) com este título, que também traz este significado.
} 
(1995): Caminhos de bosque. Se em tempos pretéritos, os da modernidade sólida, a escola estruturava os estudantes através de conceitos ético-morais com sólidos fundamentos transcendentais (na compreensão dos educadores e dos educandários), hoje, os indivíduos se constituem de mil formas que, sobretudo a mídia oferece diuturnamente. Já não há âncoras e balizas fixas que determinam os comportamentos. Mesmo as bases religiosas que forneciam bases ético-morais, hoje, se liquefazem na multiplicidade de igrejas formais e de busca de sentidos grupais informais. A pluralidade, a diversidade marcam nossos tempos. E muitas instituições educacionais que se constituíram em megaempresas econômico-financeiras já não têm seu foco nos valores humanos, mas, muito mais que isto, seu foco é o sucesso a qualquer preço. No Brasil e no mundo, preconizam-se, para a educação, habilidades e competências, cujo foco, tantas vezes se consubstancia na competitividade, no struggle for life - uma luta que não poucas vezes é feroz e violenta. Progresso e desenvolvimento são palavras que são douradas, mas que nem sempre traduzem el buen vivir (o bem viver ou viver bem), como os povos ancestrais andinos propõem.

Pode-se dizer que as mudanças de paradigmas que levam da modernidade à pósmodernidade decorrem de um número variado de razões, que não temos nem a agudeza nem espaço, nesta proposta, para determinar especificamente, quam satis (em medida satisfatória), mesmo porque não é o objetivo a que este texto se propôs. Entretanto, de algum modo, é possível afirmar que tais mudanças se filiam aos modos de subjetivação, seja na qualidade de agentes promotores ou, mesmo, de produtos destas mudanças.

Diante deste quadro, pensar as questões que inscrevem a contemporaneidade não é percorrer um caminho fácil, pois não se trata de um percurso já consolidado e que sequer tem pretensões de se consolidar. Seus temas e questões não têm um corpo teórico definitivo, conciso. Todavia, se é possível pensar um único ponto comum capaz de sustentar as distintas facetas destes tempos, resta, como perspectiva, o "caráter de mudança" (LYON, 1998). Seja o enunciado da "sociedade de vigilância" de Foucault (1977), na íntima ligação entre consumo e mídias visuais ou nas simulações percebidas por Baudrillard (1991; 2005); na metáfora da liquidez de Bauman (2001; 2009); na auto-organização, complexidade e caos de Berticelli (2006), tudo evidencia as mudanças que pluralizaram os saberes e instituíram/destituíram os sujeitos. 0 ponto é que estes autores, cada um sob uma ótica, assinalam que os acontecimentos ocorridos 
nas sociedades das últimas décadas apontam "[...] para algumas mudanças sociais e culturais importantes que estão acontecendo [...] e estas mudanças compõem o mote central das discussões que escrevem a pós-modernidade". (LYON, 1998, p.09). E aqui, urge destacar que tais mudanças impactam diretamente a educação como fenômeno social. E não seria exagero dizer que impactam de forma aguda, pois a educação é um campo de saberes de implicações amplas, abrangentes na produção das identidades.

Embora a temática seja bastante discutida e, por vezes até recusada, chegando, mesmo, a ser desdenhada, já foi pensada e anunciada por distintas frentes teóricas que sendo, não raro, divergentes, não impedem de adentrar na discussão com muito proveito. Ainda que não seja uma questão simples, pois está eivada de nuances que devem ser consideradas é, a partir daqui, a partir de autores que pensam se estamos vivendo ainda a modernidade ou já após seu fim, (capitalismo tardio, pós-modernidade, modernidade líquida, hipermodernidade etc.) que nos movemos e que podemos dizer sem medo que a pós-modernidade se sustém, sobretudo, no caráter de mudança dos paradigmas modernos, estando invariavelmente perspectivada como continuação ou oposição à modernidade.

Ao colocar em discussão os acontecimentos do presente, a conflituosa relação dos sujeitos consigo e com a sociedade, a forçosa busca de autoinventar-se passa por interrogar-nos sobre nós mesmos. Todavia, sem nos prendermos nos mesmos maquinismos heurísticos de épocas anteriores. Vale, ainda, dizer que a modernidade, lugar do homem moderno criado à imagem e semelhança de Deus e explicado por Hegel, não deixou de existir, apenas cedeu parte de seu território para a pós-modernidade, que é entendida, aqui, como sendo o estado das culturas e dos saberes, ditos assim no plural, como se posiciona Berticelli, (2006). Não podemos definir qual é o formato deste território, mas é aí que, na atualidade, habitam homens e mulheres de múltiplas cores (brancos, negros, pardos etc.), crianças, os homens das selvas, os bárbaros (no sentido em que os entendiam os gregos clássicos: não detentores da língua dominante, os helénoi) etc.

Em termos de significados culturais, a ruptura da linearidade da história possibilitou a emergência de diversas forças: sociais, culturais, econômicas, educativas, gerando uma imprevisibilidade nas formas e nos modelos da disforme massa que se move em torno das luzes de nossa época. Este é o cenário em que educação e educadores se encontram hoje. 


\section{Referências}

BAUDRILLARD, J. Simulacros e simulações. Lisboa: Relógio D’água,1991.

BAUDRILLARD, J. A arte da desaparição. Trad. Anamaria Skinner. Rio de Janeiro: Ed. UFRJ, 1997.

BAUDRILLARD, J. O sistema dos objetos. 4. ed. Trad. Zulmira R. Tavares. São Paulo: Perspectiva, 2004.

BAUDRILLARD, J. A sociedade de consumo. Trad. Artur Morão. São Paulo: Abril, 2005.

BAUMAN, Z. O mal-estar da pós-modernidade. Trad. Mauro Gama e Cláudia M. Gama. Rio de Janeiro: Zahar, 1998.

BAUMAN, Z. Modernidade e ambivalência. Trad. Marcus Penchel. Rio de Janeiro: Zahar, 1999.

BAUMAN, Z. Modernidade líquida. Trad. Plínio Denzien. Rio de Janeiro: Zahar, 2001.

BAUMAN, Z. Identidade. Trad. Carlos Alberto Medeiros. Rio de Janeiro: Zahar, 2005.

BAUMAN, Z. Vida líquida. Trad. Carlos Alberto Medeiros. Rio de Janeiro: Zahar, 2009.

BAUMAN, Z. Legisladores e intérpretes. Trad. Renato Aguiar. Rio de Janeiro: Zahar, 2010.

BERTICELLI, I. A. Epistemologia e educação: da complexidade, auto-organização e caos. Chapecó: Argos, 2006.

DELEUZE, G.; GUATTARI, F. Mil platôs: capitalismo e esquizofrenia. Trad. Ana Lúcia de Oliveira, Aurélio G. Neto e Célia P.Costa. Rio de Janeiro: Ed. 34, 1996.

DERRIDA, J. Gramatologia. Trad. Miriam Schnaiderman e Renato J. Ribeiro. São Paulo:

Perspectiva, 2008.

DIDEROT, D. O sonho de D’Alembert. In:Textos escolhidos. 2. ed. Trad. Jacó Guinsburg. São Paulo: Abril Cultural, 1985. p.93-121. [Coleção Os Pensadores].

FOUCAULT, M. Vigiar e punir: nascimento da prisão. Trad. Raquel Ramalhete. Petrópolis: Vozes, 1977.

FOUCAULT, M. Microfísica do poder. Trad. Maria Teresa de Oliveira e Roberto Machado. Rio de Janeiro: Graal, 1979.

FOUCAULT, M. Michel Foucault entrevistado por Hubert L. Dreyfus e Paul Rabinow. In:

RABINOW, P., DREYFUS, H. (orgs.). Michel Foucault - uma trajetória filosófica. Trad. Vera Porto- 
Carrero. Rio de Janeiro: Forense Universitária, 1995, p.253-278.

FOUCAULT, M. Ditos e escritos: ética, sexualidade, política. Rio de Janeiro: Forense Universitária, 2004.

FOUCAULT, M. A arqueologia do saber. Rio de Janeiro: Forense Universitária, 2009.

KAFKA, F. O processo. Trad. Modesto Carone. São Paulo: Círculo do Livro, [19--?].

LIPOVETSKY, G. Os tempos hipermodernos. Trad. Mário Vilela. São Paulo: Barcarolla, 2004.

LYOTARD, J-F. O pós-moderno. 3. ed. Trad. Pedro Henrique C. Silva. Rio de Janeiro: José Olympio, 1988.

LYON, D. Pós-modernidade. Trad. Euclides Luiz Calloni. São Paulo: Paulus, 1998.

MOREY, M. La cuestión del método. In: FOUCAULT, M. Tecnologías del yo y otros textos afines. Barcelona: Paidós Ibérica, 1991, p.9-44.

PARAÍSO, M. A. Currículo e mídia educativa brasileira: poder, saber e subjetivação. Chapecó: Argos, 2007.

VEIGA-NETO, A. Foucault \& a educação. Belo Horizonte: Autêntica, 2003.

Recebido em maio 2019.

Aprovado em outubro 2020. 